\title{
Structural Basis for the Proinflammatory Cytokine Activity of High Mobility Group Box 1
}

\author{
Jianhua Li, ${ }^{1}$ RiIKKa KoKKola, ${ }^{2}$ Siamak Tabibzadeh, ${ }^{3}$ RUnKuan Yang, ${ }^{4}$ Mahendar Ochani, ${ }^{1}$ \\ XiaOling Qiang, ${ }^{1}$ Helena E Harris, ${ }^{2}$ Christopher J Czura, ${ }^{1}$ Haichao Wang, ${ }^{1}$ Luis Ulloa, ${ }^{1}$ \\ Hong Wang, ${ }^{1}$ H ShaW WARren, $^{5}$ Lyle L Moldawer, $^{6}$ Mitchell P FinK, $^{4}$ Ulf Andersson, $^{2}$ \\ KeVIN J TraceY, ${ }^{1}$ and HuaN Yang ${ }^{1}$
}

High mobility group box 1 (HMGB1), a ubiquitous DNA-binding protein, has been implicated as a proinflammatory cytokine and late mediator of lethal endotoxemia. HMGBI is released by activated macrophages. It amplifies and extends the inflammatory response by inducing cytokine release and mediating acute lung injury, anorexia, and the inflammatory response to tissue necrosis. The kinetics of $\mathrm{HMGB} 1$ release provide a wide therapeutic window for endotoxemia because extracellular levels of HMGB 1 begin to increase 12 to $24 \mathrm{~h}$ after exposure to inflammatory stimuli. Here, we demonstrate that a DNA-binding domain of HMGB1, the B box, recapitulates the cytokine activity of full length HMGB1 and efficiently activates macrophages to release tumor necrosis factor (TNF) and other proinflammatory cytokines. Truncation of the B box revealed that the TNF-stimulating activity localizes to 20 amino acids (HMGBl amino acids 89 to 108). Passive immunization of mice with antibodies raised against $B$ box conferred significant protection against lethal endotoxemia or sepsis, induced by cecal perforation. These results indicate that a proinflammatory domain of HMGB1 maps to the highly conserved DNAbinding B box, making this primary sequence a suitable target in the design of therapeutics.

\section{INTRODUCTION}

High mobility group box 1 protein (HMGB1, previously HMG-1, amphoterin) is an abundant nuclear and cytoplasmic protein first identified in the 1970s as a 30-kDa protein associated with nuclear chromatin $(1,2)$. The HMGB1/DNA interaction has been studied for its roles in promoting formation and stability of nucleo-protein complexes, facilitating gene transcription of glucocorticoid receptors, and mediating activity of RAG recombinase (3-7). HMGB1 has 3 major structural domains: 2 DNA binding motifs, called the HMG A and HMG B boxes, and an acidic carboxyl terminus. The 2 HMG boxes are 70 to 80 amino acid L-shaped domains formed by $3 \alpha$-helical segments that are important for DNA binding $(8,9)$. HMGB1 binds to the minor groove of DNA through hydrophobic amino acids that expand the groove and facilitate the unwinding and bending of DNA, allowing formation of nucleoprotein complexes that enhance the activity of several transcription factors $(8,10)$. Disruption of the HMGB1 gene in vivo is incompatible with survival past day 2 post-partum (11).

We recently showed that HMGB1 as a late cytokine mediator of delayed endotoxin lethality (12-14). HMGB1 is released from monocytes/macrophages stimulated with endotoxin or proinflammatory cytokines (12,15). Serum HMGB1 levels are increased in critically ill patients with lethal sepsis or hemorrhagic shock. The highest levels occurred in patients that suc- cumbed to their illness $(12,16)$. Antibodies against HMGB1 confer significant protection against endotoxin-induced lethality, even when antibody administration is delayed until after the early proinflammatory cytokine response is resolved (12). Direct intratracheal administration of HMGB1 causes acute lung injury, and anti-HMGB1 antibodies confer significant protection against endotoxin-induced lung injury (14). Increased intracerebral HMGB1 levels mediate fever and anorexia (17). Like other proinflammatory cytokines (for example, tumor necrosis factor [TNF] and interleukin [IL]-1), HMGB1 is a potent activator of monocytes that stimulates the release of TNF and other products of activated macrophages (13). HMGB1 enhances plasmin formation through interaction with tissue plasminogen activating factor, is a growth factor for neuronal cultures, and mediates enhanced smooth muscle cell chemotaxis (18-20). Monocytes release HMGB1 through an atypical endolysosomal-like pathway that is activated by inflammatory stimuli (21). HMGB1 also can be released by injured or necrotic cells, and it functions as a major stimulus of necrosisinduced inflammation (22).

We recently initiated experiments to elucidate the molecular basis of the inflammatory activity of HMGB1. Surprisingly, the B box of HMGB1 proved sufficient to induce TNF release from murine macrophage-like (RAW 264.7) cell cultures (23). Based on these preliminary findings, we explored the biological effects of recombinant $\mathrm{B}$ box on a human enterocytic cell line and ileal mucosal

\footnotetext{
'Laboratory of Biomedical Science, North Shore-Long Island Jewish Research Institute, 350 Community Drive, Manhasset, NY 11030; ${ }^{2}$ Center for Molecular Medicine, Karolinska Hospital, 17176 Stockholm, Sweden; ${ }^{3}$ Department of Obstetrics and Gynecology, Stony Brook University, Stony Brook, NY 11794; ${ }^{4}$ Department of Critical Care Medicine, University of Pittsburgh Medical Center, 3550 Terrace Street, Pittsburgh, PA 15261; 5 Infectious Disease Unit, Massachusetts General Hospital, East 149 13th Street, Charlestown, MA 02129; ${ }^{6}$ Department of Surgery, University of Florida College of Medicine, Shands Hospital, 1600 SW Archer Road, Gainesville, FL 32610.
} 
permeability in vivo (24). B box induces reversible permeability of human enterocytic Caco-2 cells in a time- and dose-dependent manner in vitro and alters gastrointestinal mucosal barrier function in vivo. It remained previously unknown whether the B box is sufficient to stimulate cytokine synthesis in macrophages.

Here, we report the structural basis for the cytokine activity of HMGB1. Comparison of the macrophage-stimulating activities of truncated HMGB1 peptides nested around DNA binding domains revealed that the proinflammatory activity of HMGB1 localizes to the B box with the most significant cytokine functionality mapping to the first 20 amino acid residues of this domain (HMGB1 amino acids 89 to 108). Antibodies raised against the B box conferred significant protection against lethality following injection of mice with lipopolysaccharide (LPS) or following the induction of bacterial peritonitis. Identification of the primary structure of the inflammatory domain of HMGB1 now provides the opportunity for designing novel, structure-based therapeutics for diseases characterized by excessive HMGB1 release.

\section{MATERIALS AND METHODS}

\section{Materials}

Recombinant mouse TNF was obtained from R\&D System Inc (Minneapolis, MN, USA). Isopropyl-D-thiogalactopyranoside was purchased from Pierce Fine Chemicals (Rockford, IL, USA). Polymyxin B, D-galactosamine-HCL, lipopolysaccharide (endotoxin, E. coli. 0111:B4), and nonimmune rabbit IgG were purchased from Sigma Chemical (St. Louis, MO, USA). DNase I and 2xYT medium were obtained from Life Technologies (Grand Island,


antibodies were purchased from Santa Cruz Biotechnology Inc (Santa Cruz, CA, USA). Primary antibodies used for kinase assays, phospho-stress activated protein kinase (SAPK)/Jun N-terminal kinases (JNK) (Thr183/Tyr185, Cat \#9251) and Phospho-p38 MAP kinase (Thr180/Tyr182, Cat \#9211) were obtained from Cell Signaling Technology (Beverly, MA, USA). HRP-linked secondary anti-rabbit IgG was purchased from Amersham Pharmacia Biotech (Cat \#NA 934, Uppsala, Sweden).

\section{Peptide Synthesis}

Peptides were synthesized and HPLC purified at Utah State University Biotechnology Center (Logan, Utah, USA) at 90\% purity. Endotoxin was not detectable in the synthetic peptide preparations as measured by Limulus assay.

\section{Cell Culture}

Murine macrophage-like RAW 264.7 cells and murine fibroblast L929 cells (American Type Culture Collection, Rockville, MD, USA) were cultured in RPMI 1640 medium (RAW 264.7 cells) or DMEM (L929 cells) (Life Technologies, Grand Island, NY, USA) supplemented with $10 \%$ heat inactivated fetal bovine serum (Gemini, Catabasas, CA, USA), penicillin (50 units/mL), and streptomycin $(50 \mu \mathrm{g} / \mathrm{mL})$ (Life Technologies) in a humidified incubator with $5 \% \mathrm{CO}_{2}$ and $95 \%$ room air. Cells were used at $90 \%$ confluence and treatment was carried out in serum-free Opti-MEM I medium (Life Technologies). Thioglycollate-elicited peritoneal macrophages from $\mathrm{C} 3 \mathrm{H} / \mathrm{HeJ}$ mice were obtained by peritoneal lavage with $5 \mathrm{~mL}$ HEPES-buffered RPMI medium as previously described (13). Cells were cultured in RPMI 1640 medium containing $10 \%$ fetal bovine serum, penicillin, and streptomycin as described above.

\section{Polymerase Chain Reaction (PCR)}

Recombinant human HMGB1 (651bp) was cloned by PCR amplification from a human brain Quick-Clone cDNA (Clontech, Palo Alto, CA, USA) using the following primers: forward primer, $5^{\prime}$ GATGGGCAAAGGAGATCCTAAG 3', and reverse primer, 5' GCGGCCGC TTATTCATCATCATCATCTTC 3'. A Not I site was added to the reverse primer as underlined. The truncated form of human HMGB1 was cloned by PCR amplification from a human Brain Quick-Clone cDNA (Clontech). The primers were B box (233 bp), 5' AAG TTC AAG GAT CCC AAT GCA AAG 3' and 5' GCG GCC GCT CAA TAT GCA GCT ATA TCC TTT TC 3'; and A box (261 bp), 5' GAT GGG CAA AGG AGA TCC TAA G 3' and 5' TCA CTT TTT TGT CTC CCC TTT GGG 3'. A stop codon was added to each mutant to ensure the accuracy of protein size.

\section{Protein Expression and Purification}

PCR products were subcloned onto pCRII-TOPO vector EcoR I sites using TA cloning method, per the manufacturer's instructions (Invitrogen, Carlsbad, CA, USA). After amplification, the PCR product was digested with EcoR I and subcloned into an expression vector (pGEX) with a glutathione S-transferase (GST) tag (Pharmacia, Piscataway, NJ, USA). Correct orientation in positive clones was confirmed by DNA sequencing of both strands. The recombinant plasmids were transformed into protease deficient E. Coli strain BL21 (Novagen, Madison, WI, USA) and incubated in $2 \times Y T$ medium containing ampicillin $(50 \mu \mathrm{g} / \mathrm{mL})$ for 5 to $7 \mathrm{~h}$ at $37^{\circ} \mathrm{C}$ with vigorous shaking until optical density at $\mathrm{A}_{600}$ achieves 1 to 1.5. Fusion protein expression was induced by addition of $1 \mathrm{mM}$ isopropyl-D-thiogalactopyranoside for $3 \mathrm{~h}$ at 37 or 25 ${ }^{\circ} \mathrm{C}$ (for B box). Bacteria were sonicated in ice-cold phosphatebuffered saline (PBS) plus $1 \times$ protease inhibitor cocktail (Sigma Chemical) and $1 \mathrm{mM}$ phenylmethylsuphonyl fluoride (PMSF). After centrifugation $(8000 \times g)$ to remove bacterial debris, the bacterial lysate was subjected to affinity purification using the Glutathione Sepharose resin column (Pharmacia). GST vector protein was expressed, purified, and used as the control for experiments using recombinant GST-HMGB1 proteins. Protein elute was dialyzed extensively against PBS to remove excess amount of reduced glutathione, passed over the polymyxin B column (Pierce, Rockford, IL, USA), lyophilized, and redissolved in sterile PBS before use. The integrity of proteins was verified by SDSPAGE with Coomassie Blue staining. Purity was predominantly over $85 \%$.

\section{Cleavage of GST Tag from HMGB1 or B Box}

After binding of HMGB1- or B box-containing bacteria lysate to Glutathione Sepharose affinity column, the column was washed with 10 column volumes of ice-cold PBS to remove unbound proteins and then equilibrated with 10 column volumes of protease buffer (50 mM Tris $\mathrm{HCl}, \mathrm{pH} 8,150 \mathrm{mM} \mathrm{NaCl}$ and $1 \mathrm{mM}$ EDTA). For each milliliter of Glutathione Sepharose beads, 80 units of Precision protease were added (2000 units/mL, Pharmacia) in $1 \mathrm{~mL}$ pro- 
tease buffer with $1 \mathrm{mM}$ dithiothreitol. Digestion was carried out at room temperature for $3 \mathrm{~h}$ with gentle rotation. Once digestion was complete, the suspension was centrifuged at $500 \times g$ for $5 \mathrm{~min}$ to pellet the Sepharose beads; the eluate containing HMGB1 or B box protein was collected.

\section{DNase I Treatment}

After binding of bacterial lysate containing HMGB1 mutant proteins to GST column, DNase I was added at 80 units/mL Glutathione Sepharose beads and incubated for $20 \mathrm{~min}$ at room temperature in buffer containing $100 \mathrm{mM} \mathrm{NaAc}(\mathrm{pH} \mathrm{5)}$ and $5 \mathrm{mM}$ $\mathrm{MgCl}_{2}$. Column was washed with 5 column volumes of ice-cold PBS; proteins then were eluted with reduced glutathione as described by the manufacturer (Pharmacia). Degradation of DNA was verified by ethidium bromide staining of the agarose gel containing HMGB1 proteins before and after DNase I treatment.

\section{LPS Content}

The protein eluates were passed over a polymyxin B column to remove any contaminating LPS. The LPS content of proteins used in cell cultures was measured by the chromogenic Limulus amebocyte lysate assay (BioWhittaker Inc, Walkersville, MD, USA). LPS content in HMGB1 was $219 \mathrm{pg} / \mu \mathrm{g}$ protein, in B box was 19 $\mathrm{pg} / \mu \mathrm{g}$, in A box was $16 \mathrm{pg} / \mu \mathrm{g}$, and in GST vector was $4 \mathrm{pg} / \mu \mathrm{g}$. For stimulation experiments, polymyxin B was added to cell culture medium at 6 units polymyxin B/pg LPS.

\section{RNA Extraction and RNase Protection Assay}

For mRNA measurement, RAW 264.7 cells were plated in $100-\mathrm{mm}$ plates and treated in Opti-MEM I medium containing B box or the vector alone for 0 to $24 \mathrm{~h}$. Cells were scraped off the plate and total RNA was isolated by RNAzol B method according to the manufacturer's instructions (Tel-Test “ $B$ ” Inc, Friendswood, TX, USA). TNF mRNA (287 bp, BD PharMingen, San Diego, CA, USA) was measured by RNase protection assay (Ambion, Austin, TX, USA). Equal loading and the integrity of RNA was verified by ethidium bromide staining of the RNA sample on agarose-formaldehyde gel (data not shown).

\section{Nuclear Extract Preparations}

RAW 264.7 cells were plated at $10^{6}$ cells per 6 -cm dish and were incubated with medium alone (control) or B box for various time periods as indicated. Cells were washed twice with ice-cold PBS and scraped off the plate in $1 \mathrm{~mL}$ PBS containing $2 \%$ FBS. The cells were transferred to a $1.5 \mathrm{~mL}$ microfuge tube, centrifuged at 14000 $\times g$ for $10 \mathrm{~s}$ and supernatant was discarded. The cell pellets were suspended in buffer I ( $10 \mathrm{mM} \mathrm{KCL}, 1.5 \mathrm{mM} \mathrm{MgCl} 2,0.3 \mathrm{M}$ sucrose, $500 \mu \mathrm{M}$ PMSF, $1.0 \mathrm{mM}$ sodium orthovanadate, $1 \mathrm{mM}$ DTT, $10 \mathrm{mM}$ Tris $\mathrm{HCl}, \mathrm{pH} 7.8$ ) and incubated at room temperature for $15 \mathrm{~min}$. After adding Nonidet ${ }^{\circledR} \mathrm{P} 40$ to final concentration of $10 \%$, the nuclei were isolated by centrifugation at $310 \times g$ for $3 \mathrm{~min}$ and the supernatant was discarded. The nuclear pellets were gently suspended in buffer II (500 $\mu$ M PMSF, $1.0 \mathrm{mM}$ Na orthovanadate, 1 $\mathrm{mM}$ DTT, $420 \mathrm{mM} \mathrm{KCl}, 1.5 \mathrm{mM} \mathrm{MgCl} 2,20 \%$ glycerol, $10 \mathrm{mM}$ Tris $\mathrm{HCl}, \mathrm{pH} 7.8$ ) and incubated at room temperature for $15 \mathrm{~min}$. Nuclear extracts were centrifuged at $14000 \times g$ for $10 \mathrm{~min}$ and supernatants were transferred to a fresh tube; protein concentra- tion was determined by Bradford assay (Bio-Rad, Hercules, CA). Nuclear extracts were stored at $-80^{\circ} \mathrm{C}$ until use.

\section{Electrophoretic Mobility Shift Assay (EMSA)}

The sequence of the double-stranded nuclear factor NF- $\mathrm{B}$ oligonucleotide was as follows: sense, 5' AGT TGA GGG GAC TTT CCC AGG C 3'; antisense, 3' TCA ACT CCC CTG AAA GGG TCC G 5' (Promega, Madison, WI, USA). The oligonucleotides were end-labeled with $\alpha_{-}{ }^{32}$ P ATP (New England Nuclear, Boston, MA, USA) using T4 polynucleotide kinase (Promega). Nuclear protein $(3 \mu \mathrm{g})$ was incubated with $\alpha-{ }^{32} \mathrm{P}$-labeled NF- $\mathrm{B}$ probe solution in band-shift buffer (65 mM NaCl, $1 \mathrm{mM}$ DTT, $0.14 \mathrm{mM}$ EDTA, 8\% glycerol and $13 \mathrm{mM}$ HEPES, $\mathrm{pH}$ 8.0) in the presence of $2 \mu \mathrm{g}$ poly $[\mathrm{d}(\mathrm{I}-\mathrm{C})]$ (Boehringer Mannheim, Indianapolis, IN, USA) for $20 \mathrm{~min}$ at room temperature. For competition experiments, super-shift assays were performed by incubation of nuclear extracts with either 100-fold molar excess of unlabelled oligonucleotides added simultaneously with the labeled probe or preincubated with nonimmune antibodies $(2 \mu \mathrm{g} / \mathrm{mL})$ for $1 \mathrm{~h}$ prior to addition of radiolabelled probe. The binding reaction mixture was electrophoresed on $4 \%$ nondenaturing polyacrylamide gels containing 5\% glycerol and $0.25 \times$ TBE buffer. After PAGE, the gels were dried and exposed to Biomax-5 film (Eastman Kodak, Rochester, NY, USA) at $-80{ }^{\circ} \mathrm{C}$ overnight using an intensifying screen and densitometric analysis was performed.

\section{Kinase Assays}

Thioglycollate-elicited primary macrophages from $\mathrm{C} 3 \mathrm{H} / \mathrm{HeJ}$ mice were plated at $2 \times 10^{6} /$ well in $6-\mathrm{cm}$ dish and were stimulated with B box or HMGB1 $(10 \mu \mathrm{g} / \mathrm{mL})$ for 0 to $60 \mathrm{~min}$. After stimulation, cells were washed with ice-cold PBS and lysed with SDS sample buffer containing vanadate and protease inhibitor cocktail (Sigma). Samples were sonicated, boiled for $5 \mathrm{~min}$, and centrifuged $\left(10000 \times g, 5 \mathrm{~min}, 4^{\circ} \mathrm{C}\right)$; and then analyzed by Western immunoblotting.

\section{Antibody Production}

Polyclonal antibodies against $\mathrm{B}$ box were raised in rabbits (Cocalico Biologicals, Inc, Reamstown, PA, USA) or hens (Aves Labs, Tigard, OR, USA) and assayed for titer by Western blotting. IgG was purified from anti-B box antiserum using Protein A agarose according to manufacturer's instructions (Pierce, Rockford, IL, USA). IgY was isolated from B box-immunized egg yolk and was made available by Aves Labs (Tigard, OR, USA). Anti-B box rabbit antibodies were affinity purified by using cyanogens bromide-activated Sepharose beads following standard procedures and were made available from Cocalico Biologicals Inc. Neutralizing activity of anti-HMGB1 was confirmed in macrophage cultures exposed to recombinant HMGB1 and assayed for ability of antibodies to inhibit TNF release.

\section{Animal experiments}

Male Balb/C and $\mathrm{C} 3 \mathrm{H} / \mathrm{HeJ}$ (6 to $8 \mathrm{wk}$ ) mice were purchased from Harlan Sprague-Dawley (Indianapolis, IN, USA) and allowed to acclimate for $7 \mathrm{~d}$ before use in the experiment. Mice were housed in the North Shore University Hospital Animal Facility under standard temperature, light and dark cycle. All animal proce- 
$\underline{B \text { box mutants }} \quad \underline{\text { TNFrelease }(\mathrm{pg} / \mathrm{mL})}$

\begin{tabular}{|c|c|}
\hline Full length HMGBI & $7224 \pm 208$ \\
\hline B box: 74 amino acids & $5675 \pm 575$ \\
\hline-20 & $2100 \pm 756$ \\
\hline $16-35$ & $100+10$ \\
\hline$\underline{30-49}$ & $120 \pm 75$ \\
\hline $45-64$ & $100 \pm 36$ \\
\hline $60-74$ & $100 \pm 20$ \\
\hline
\end{tabular}

Figure 1. TNF stimulating activity of $\mathrm{HMGB}$ proteins and peptides. Murine macrophage-like RAW 264.7 cells in 24-well culture plate were treated with $\mathrm{HMGB} 1$ or $\mathrm{B}$ box at $1 \mu \mathrm{g} / \mathrm{mL}$, or synthetic peptides at $10 \mu \mathrm{g} / \mathrm{mL}$, as indicated, for $8 \mathrm{~h}$; TNF release in the supernatants was measured by a murine fibroblast L929 cytotoxicity bioassay. Data shown are mean \pm SEM, $n=3$ to 10 separate experiments; each done in duplicate and validated using 3 separate lots of synthetic peptides.

dures have been reviewed and approved by the IACUC of North Shore University Hospital Animal Facility.

\section{LPS Lethality}

Balb/C mice were given an $\mathrm{LD}_{75}$ dose of LPS (15 mg/ $\mathrm{kg}$ ) injected intraperitoneally and treated with either purified anti-B box IgG antibody raised in rabbits (and nonimmune rabbit IgG as control, $600 \mu \mathrm{g}$ per mouse each time, intraperitoneally) or purified anti-B box IgY at 60 or $600 \mu \mathrm{g}$ per injection. Injections were given at time 0,12 , and $24 \mathrm{~h}$ after LPS administration. Mortality was monitored daily for up to $2 \mathrm{wk}$.

\section{Cecal Ligation and Puncture (CLP)}

CLP was performed as described previously (25). Briefly, Balb/C mice were anesthetized with an intramuscular injection of 75 $\mathrm{mg} / \mathrm{kg}$ Ketamine (Fort Dodge, Fort Dodge, IA, USA) and $20 \mathrm{mg} / \mathrm{kg}$ xylazine (Boehringer Ingelheim, St. Joseph, MO, USA). A 15-mm midline incision was performed, and the cecum was exposed. A 6-0 prolene suture ligature was placed $5 \mathrm{~mm}$ from the cecal tip, away from the ileocecal valve. The ligated cecal stump was then punctured once with a 22-gauge needle, without direct extrusion of stool. The cecum was replaced back into its normal intra-abdominal position. The abdomen wound was closed with a running suture in 2 layers, peritoneum and fascia separately, to prevent leakage of fluid. All animals were resuscitated with a normal saline solution administered subcutaneously at $20 \mathrm{~mL} / \mathrm{kg}$ of body weight. Each mouse received a subcutaneous injection of imipenem $(0.5 \mathrm{mg} /$ mouse in $200 \mu \mathrm{L}$ sterile saline) (Primaxin, Merck \& Co Inc, West Point, PA, USA) $30 \mathrm{~min}$ after the surgery. Anti-B box rabbit IgG (60 or $600 \mu \mathrm{g} /$ mouse in $400 \mu \mathrm{L}$ sterile PBS) were given intraperitoneally twice daily for $3 \mathrm{~d}$ beginning 12, 24, or $36 \mathrm{~h}$ after CLP. Control groups received injections of matched doses of non-immune IgG. Mortality was recorded for up to $1 \mathrm{wk}$ after the procedure; survivors were followed for $2 \mathrm{wk}$ to ensure no late mortalities had occurred.

\section{B Box Toxicity}

The D-galactosamine-sensitized model has been described $(26,27)$. Mice were injected intraperitoneally with $20 \mathrm{mg}$ of D-galactosamine-HCL/mouse in $200 \mu \mathrm{L}$ PBS and B box, A box, or vector protein in the doses indicated in $200 \mu \mathrm{L}$ PBS. Mortality was recorded daily for up to $72 \mathrm{~h}$ after injection; survivors were followed for $2 \mathrm{wk}$.

\section{Histological Evaluation}

D-galactosamine-sensitized mice treated with B box for $7 \mathrm{~h}$ were euthanized; organs were harvested and fixed in $10 \%$ formaldehyde. Tissues sections were stained with hematoxylin and eosin for histological evaluation (Criterion Inc, Vancouver, BC, Canada).

\section{Cytokine Measurements}

The concentrations of TNF were determined using a standard L929 cytotoxicity bioassay as previously described (28). IL-1 $\beta$, IL-6, and IL-10 levels were determined by commercially obtained ELISA kits according to the manufacturer's (R\&D System Inc, Minneapolis, MN, USA).

\section{Statistical Analysis}

Data are presented as means \pm SEM. Differences between treatment groups were determined by Student's $t$ test, 1-way ANOVA followed by the least significant difference test or Fisher's exact test; $P$ value $<0.05$ was considered statistically significant.

\section{RESULTS}

\section{The B Box of HMGB1 Is Essential for Proinflammatory} Cytokine Functionality

To elucidate the minimal primary sequence requirements for the proinflammatory cytokine-stimulating activity of HMGB1, full length and truncated forms of HMGB1 were expressed, purified, and added to murine macrophage-like RAW 264.7 cultures. Full length (wild-type) and HMGB1 B box constructs each stimulated macrophage TNF release, indicating that the deleted sequences are not essential for proinflammatory cytokine-stimulating activity (Figure 1). The A box truncate, which was devoid of B box, did not significantly stimulate TNF release, indicating that the TNFstimulating functionality of HMGB1 resides in the primary sequence of the B box (HY and KJT, submitted). We observed comparable TNF-stimulating activity by HMGB1 or B box after removing GST tag or DNase treatment (data not shown), indicating that the cytokine-stimulating activity resides within the protein itself. To determine if shorter domains within the B box are capable of stimulating cytokine release, overlapping synthetic 20residue peptides were incubated with RAW 264.7 cell cultures. Analysis of the culture medium revealed that the first 20 residues of B box (B1-B20, corresponding to HMGB1 residues 89 to 108) specifically stimulated TNF release (see Figure 1). Other 20residue peptides, corresponding to residues 109 through 153 of HMGB1, failed to stimulate TNF release, giving direct evidence that the minimal primary sequence requirements for significant macrophage stimulating activity map to the first 20 amino acids of the B box domain. B box also dose-dependently stimulated the release of IL-1 $\beta$ and IL-6 in macrophage cultures, an activity 
A
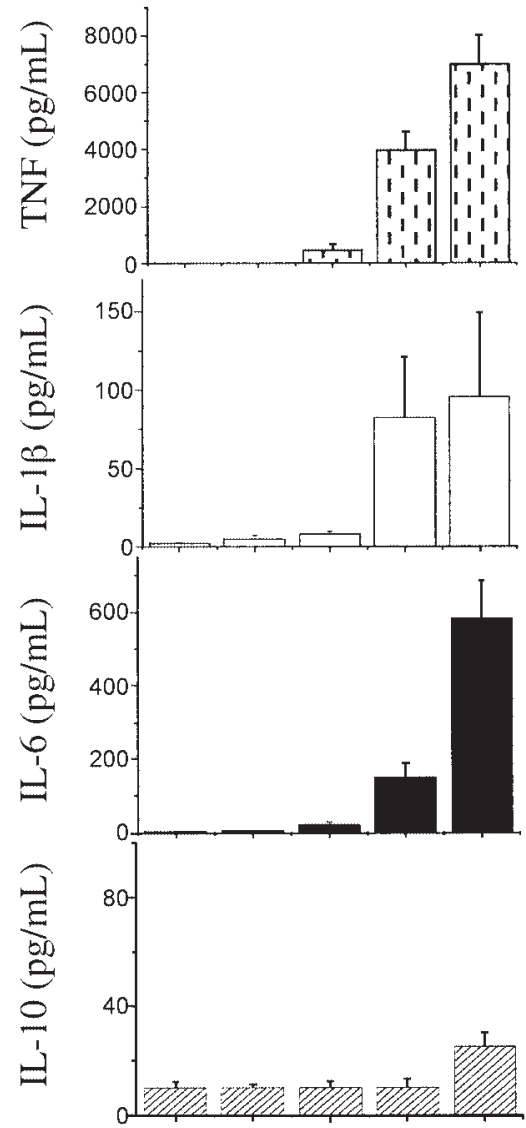

B Box $(\mu \mathrm{g} / \mathrm{mL}) \quad 0 \quad 0.01 \quad 0.1 \quad 1 \quad 10$
B

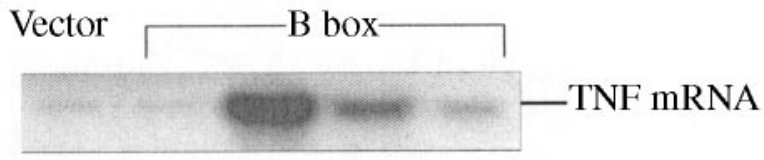

$\begin{array}{llllll}\text { Time (hours) } & 4 & 0 & 4 & 8 & 24\end{array}$

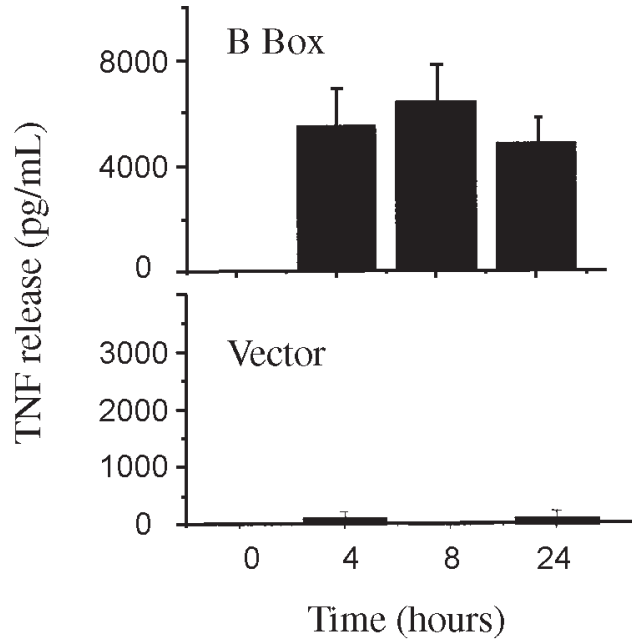

C

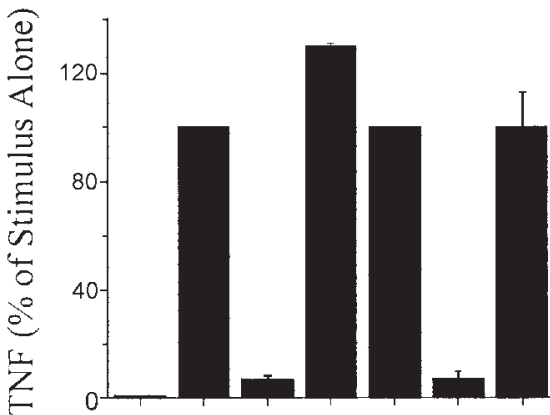

$\begin{array}{lccccccc}\text { HMGB1 }(\mu \mathrm{g} / \mathrm{mL}) & - & 1 & 1 & 1 & - & - & - \\ \text { B Box }(\mu \mathrm{g} / \mathrm{mL}) & - & - & - & - & 10 & 10 & 10 \\ \text { Anti-B Box }(\mu \mathrm{g} / \mathrm{mL}) & - & - & 25 & - & - & 100 & - \\ \operatorname{IgG}(\mu \mathrm{g} / \mathrm{mL}) & - & - & - & 25 & - & - & 100\end{array}$

Figure 2. B box stimulates cytokine release in vitro. A: B box stimulates TNF, IL-6, and IL-1 $\beta$ release from macrophage cultures. RAW 264.7 cells in $24-w e l l$ culture dishes were stimulated with B box at 0 to $10 \mu \mathrm{g} / \mathrm{mL}$ for $10 \mathrm{~h}$; conditioned media were harvested for cytokine assays. B box stimulated TNF, IL-1 $\beta$, and IL-6 (but not IL-10) release in a dose-dependent manner. Data shown are mean \pm SEM, $n=5$ independent experiments. B: B box stimulates TNF and TNF mRNA in a time-dependent manner. Supernatants of RAW 264.7 cells stimulated with B box or GST vector ( $10 \mu \mathrm{g} / \mathrm{mL}$ ) for 0 to $24 \mathrm{~h}$ were analyzed for TNF levels by L929 cytotoxicity assay. B box-induced TNF release in a time-dependent fashion as compared with vector protein. $n=3$ to 5 independent experiments. Total RNA was isolated from RAW 264.7 cells stimulated with B box or vector alone as described in Materials and Methods. Levels of TNF mRNA were measured by RNase protection assay (Materials and Methods). Data are representative of 3 separate experiments. C: Anti-B box antibody specifically inhibits HMGB1- and B box-dependent TNF stimulation. Sub-confluent RAW 264.7 cells in 24-well dishes were treated with HMGB 1 $(1 \mu \mathrm{g} / \mathrm{mL})$ or B box $(10 \mu \mathrm{g} / \mathrm{mL})$ for $10 \mathrm{~h}$ with or without affinity purified rabbit anti-B box antibody or non-immune IgG added. The TNF-inducing activity was expressed as a percentage of the activity achieved with stimulus alone and the activity of other proteins expressed as percent of $\mathrm{HMGB} 1$ or B box alone. TNF release for HMGB1 alone $(1 \mu \mathrm{g} / \mathrm{mL})=10592 \pm 3210 \mathrm{pg} / \mathrm{mL}$ and for B box $(10 \mu \mathrm{g} / \mathrm{mL})=7828 \pm 3953 \mathrm{pg} / \mathrm{mL}$. $n=3$ to $5 \mathrm{separate}$ experiments.

shared with full length HMGB1 (Figure 2A, 13). Interestingly, $B$ box failed to induce the release of the anti-inflammatory cytokine, IL-10, suggesting that B box selectively triggers the release of proinflammatory cytokines from macrophages. Exposure of macrophage cultures to $B$ box significantly enhanced the accumulation of TNF mRNA; levels were increased for more than $8 \mathrm{~h}$ after B box was added to the cultures (see Figure 2B). We observed that recombinant B box and a fully synthetic B box (Innovagen AB Inc,
S-223 70 Lund, Sweden) each stimulated TNF by RAW 264.7 cell culture, indicating that the macrophage stimulating effect of recombinant B box was specific (data not shown). Further evidence of specificity was obtained using affinity purified rabbit anti-B box antibodies, which significantly inhibited TNF release in cultures exposed to either full length HMGB1 or B box (see Figure 2C). In separate studies we also examined the inducible release of TNF from primary peritoneal macrophages from LPS-resistant 
$\mathrm{C} 3 \mathrm{H} / \mathrm{HeJ}$ mice, an inbred strain that is resistant to the proinflammatory effects of LPS due to a mutation in the gene coding for Toll-like receptor 4 (29). HMGB1 and B box each stimulated TNF release from $\mathrm{C} 3 \mathrm{H} / \mathrm{HeJ}$ macrophages (data not shown), indicating that HMGB1 and B box are effective in the absence of LPS receptor signal transduction. Collectively, these data reveal that the proinflammatory domain of HMGB1 maps to primary sequences within the $B$ box and that the B box alone is sufficient to specifically recapitulate the cytokine stimulating effects of full length HMGB1.

\section{The B Box Recapitulates the Lethality of Full Length HMGB1 In Vivo, and Anti-B Box Antibodies Attenuate Endotoxin and Sepsis Lethality}

To assess whether the B box itself can mediate lethality in vivo, highly purified B box was administered to mice in a standardized D-galactosamine sensitized mouse model of lethality $(26,27)$. Administration of B box caused significant dose-dependent lethality in Balb/C mice whereas lethality did not occur in response to HMGB1 A box or control protein purified from vectors lacking the B box (Table 1). Systemic administration of B box also was lethal to D-galactosamine-sensitized, endotoxin-resistant $(\mathrm{C} 3 \mathrm{H} / \mathrm{HeJ})$ mice (data not shown). Exposure to B box caused significant increases in serum IL-6 and IL-1 $\beta$ levels in mice after $7 \mathrm{~h}$;
Table 1. Toxicity of B box on D-galactosamine sensitized Balb/C mice ${ }^{a}$ Protein (mg/mouse) Survival (alive/total)

\begin{tabular}{lcc}
\hline Control & - & $10 / 10$ \\
Vector & 0.1 & $2 / 2$ \\
& 1.0 & $3 / 3$ \\
B box & 0.1 & $6 / 6$ \\
& 1.0 & $2 / 8 \mathrm{~b}$ \\
A box & 1.0 & $10 / 10$ \\
\hline
\end{tabular}

aBalb/C mice received D-galactosamine- $\mathrm{HCl}(20 \mathrm{mg} / \mathrm{mouse}$, in $200 \mu \mathrm{L}$ PBS, intraperitoneally) with B box, A box, or vector proteins as indicated (in $200 \mu \mathrm{L}$ volume, intraperitoneally). Mortality was recorded for up to $72 \mathrm{~h}$ and followed for $2 \mathrm{wk}$ to monitor any late deaths.

b $p<0.05$ compared with control group tested by Fisher's exact test.

serum TNF was not increased at this time point (Figure 3A). Hematoxylin- and eosin-stained sections of heart, kidney, liver, and lung collected $7 \mathrm{~h}$ after administration of B box revealed no significant abnormal morphologic changes in the lung or kidney (not shown). Examination of sections from the heart, however, revealed evidence of ischemia with loss of cross striation and amorphous pink cytoplasm in myocardial fibers. Sections from liver showed mild acute inflammatory responses with some hepatocyte dropout and apoptosis and occasional polymorphonuclear leukocytes (see Figure 3B). These specific pathologi-
A



B

Control B Box



Figure 3. B box is toxic in vivo. A: Serum IL-6 and IL-1 $\beta$ levels were elevated in mice treated with B box. Balb/C mice were injected intraperitoneally with $20 \mathrm{mg}$ D-galactosamine-HCL per mouse (in $200 \mu \mathrm{L}$ PBS) and $1 \mathrm{mg}$ of either B box or vector protein (in $200 \mu \mathrm{L}$ PBS). Blood was obtained $7 \mathrm{~h}$ later; serum was analyzed for TNF, IL-1 $\beta$, and IL- 6 by ELISA ( $n=4$ to 7 mice per group). ${ }^{*} P<0.05$ compared with control. B: Histopathology of tissues of $B$ box-treated Balb/C mice. Mice (3 per group) received D-galactosamine ( $20 \mathrm{mg} / \mathrm{mouse}$ ) plus B box or vector ( $1 \mathrm{mg} / \mathrm{mouse}$, intraperitoneally). The mice were sacrificed $7 \mathrm{~h}$ later by decapitation. Tissues were harvested and fixed in $10 \%$ buffered formaldehyde. Paraffin-embedded tissue sections were prepared and stained with hematoxylin and eosin for histological evaluation (Criterion Inc, Vancouver, BC, Canada). Compared with the control mice, B box treatment caused ischemia changes and loss of cross striation in myocardial fibers in the heart (arrow). Liver showed most of the damage by B box as illustrated by acute active hepatitis. Apoptotic hepatocytes are seen surrounded by polymorphonuclear leukocytes (arrow). 


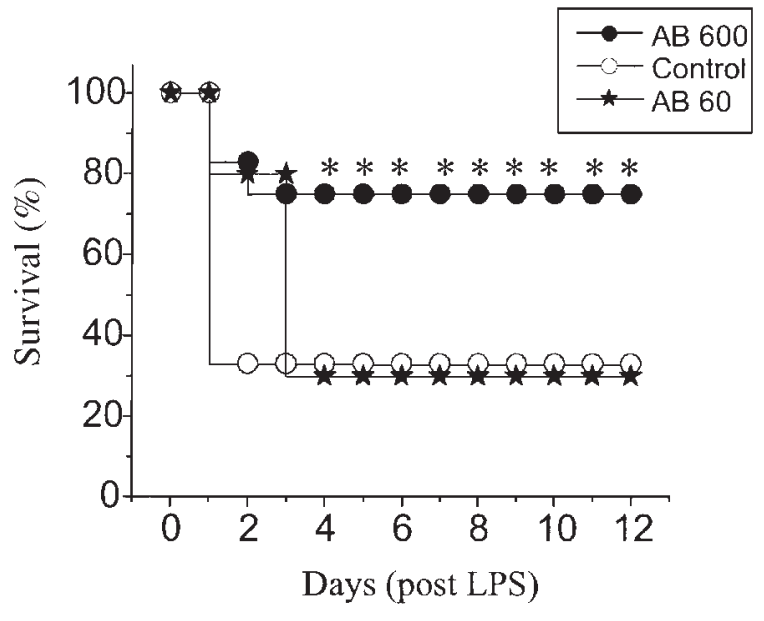

Figure 4. Anti-B box antibodies confer protection against LPS lethality in mice. Male Balb/C mice (10 to 18 per group) were treated with an $L_{75}$ dose of LPS $(15 \mathrm{mg} / \mathrm{kg}$, intraperitoneally). IgY purified anti-B box antibodies or nonimmune IgY 60 or $600 \mu \mathrm{g} /$ mouse each time, intraperitoneally) was given at time 0,12 , and $24 \mathrm{~h}$ after LPS administration. *P < 0.05 compared with control as tested by Fisher's exact test.

cal changes were comparable to those observed after administration of full length HMGB1 (data not shown), confirming that the $B$ box itself recapitulates the lethal pathological response to HMGB1 in vivo.

To determine whether antibodies targeting the B box confer protection against delayed endotoxin lethality, Balb/C mice were passively immunized with neutralizing anti-B box IgY antibodies or irrelevant control IgY. Administration of anti-B box antibodies significantly and dose-dependently protected against lethal endotoxemia (Figure 4), and improved survival from $31 \%$ in mice treated with irrelevant IgY to $73 \%$ treated with anti-B box antibodies $(P<0.05)$. Similar results were obtained by using neutralizing anti-B box rabbit IgG (survival in anti-B box $=62 \%$ compared with survival in non-immune rabbit $\mathrm{IgG}=27 \% ; n=26$ mice per group, $P<0.05)$. HMGB1 levels also are increased significantly in murine sepsis induced by cecal ligation and puncture and the kinetics of HMGB1 release is delayed in comparison to endotoxin-induced responses (HY and KJT, manuscript submitted). To determine whether anti-B box is effective in rodent models of sepsis induced by active infection, mice were subjected to cecal ligation and puncture to induce peritonitis and sepsis, and passively immunized with anti-B box antibodies. Administration of IgG purified anti-B box rabbit antibodies $12 \mathrm{~h}$ after the onset of cecal perforation significantly improved survival (survival in mice treated with control $\operatorname{IgG}=22 \%$ compared with survival in mice receiving anti-B box $\operatorname{IgG}=65 \% ; n=18$ to 20 per group, $P<0.03$, Table 2 ). Similar results were obtained when antibody treatment was initiated $24 \mathrm{~h}$ after the surgery (survival in nonimmune $\operatorname{IgG}$ group $=27 \%$ compared with survival in anti-B box $=72 \% ; n=$ 18 per group, $P<0.03$ ). Delaying the 1 st dose of antibodies for $36 \mathrm{~h}$ after cecal ligation and puncture failed to confer protection indicating that anti-B box antibodies can effectively target HMGB1 for at least $24 \mathrm{~h}$ after the onset of sepsis. Antibody dose-response studies revealed that neutralizing antibodies directed against the B box specifically protect against the toxicity of full-length HMGB1 during endotoxemia and sepsis (see Table 2).

\section{Signal transduction pathways of HMGB1 and B box}

To determine the molecular mechanism of B box action, we studied signal transduction pathways of HMGB1 and B box. Stimulation of macrophages by HMGB1 and B box was associated with activation of signaling mediators including p38 MAP and SAPK/JNK kinases in macrophage cultures obtained from LPSresistant $\mathrm{C} 3 \mathrm{H} / \mathrm{HeJ}$ mice (Figure 5A). HMGB1 and B box stimulated the phosphorylation of p38 MAP and SAPK/JNK kinases, beginning within $15 \mathrm{~min}$ after exposure of the cultures to HMGB1. By analysis of nuclear extracts by electrophoretic mobility shift assay with ${ }^{32} \mathrm{P}$-labeled NF- $\mathrm{B}$ probe we observed that B box significantly stimulated nuclear translocation of NF-кB. Nuclear translocation of NF- $\kappa \mathrm{B}$ was activated within $10 \mathrm{~min}$ and remained activated for at least $24 \mathrm{~h}$ (see Figure 5B). This kinetic profile is similar to the response activated by other cytokines $(30,31)$ and corresponds to the timeframe of HMGB1- or B box-induced TNF mRNA expression and TNF release (see Figure $2 \mathrm{~B}$ ). To identify the NF- $\mathrm{B}$ subunits involved in B box-induced intracellular signaling, nuclear extracts prepared from B box-stimulated RAW 264.7 cells were analyzed by supershift assay using ${ }^{32} \mathrm{P}$-labeled oligonucleotides that contain the consensus sequences necessary for NF- $\mathrm{\kappa B}$ to bind to DNA. Unlabeled NF-кB-specific DNA probes, but not unlabeled irrelevant oligonucleotides corresponding to the DNA binding consensus sequence of hypoxia-induced factor 1 displaced the NF-кB-DNA complex, indicating specificity for the NF$\kappa \mathrm{B}$ consensus sequences (see Figure 5B). Anti-p65 IgG caused a significant supershift in protein/DNA complex mobility, indicating that the p65 subunit is a component of the complex activated by HMGB1 and B box (see Figure 5B). Thus, B box activates macrophage signal transduction through 2 pathways (stress kinases and NF- $\mathrm{KB}$ ) that have been previously implicated in controlling the acute inflammatory response (30-32).

\section{Table 2. Anti-B box antibodies protect against CLP lethality ${ }^{a}$}

\begin{tabular}{ll} 
Treatment & \multicolumn{1}{c}{$\begin{array}{c}\text { Survival \% } \\
\text { (alive/total) }\end{array}$} \\
\hline $600 \mu \mathrm{g} / \mathrm{mouse}$ beginning $12 \mathrm{~h}$ after CLP & $22(4 / 18)$ \\
Control & $65(13 / 20)^{\mathrm{b}}$ \\
Anti-B box & \\
$600 \mu \mathrm{g} / \mathrm{mouse}$ beginning $24 \mathrm{~h}$ after CLP & $27(5 / 18)$ \\
Control & $72(13 / 18)^{\mathrm{b}}$ \\
Anti-B box & \\
$600 \mu \mathrm{g} /$ mouse beginning $36 \mathrm{~h}$ after CLP & $25(3 / 12)$ \\
Control & $33(4 / 12)$ \\
Anti-B box & \\
$60 \mu \mathrm{g} / \mathrm{mouse}$ beginning $24 \mathrm{~h}$ after CLP & $33(9 / 27)$ \\
Control & $29(8 / 27)$ \\
Anti-B box
\end{tabular}

aCLP was performed on Balb/C mice. IgG purified anti-B box rabbit antibodies or nonimmune-lgG were injected intraperitoneally twice daily beginning at times indicated and continued twice daily for $3 \mathrm{~d}$. Survival was monitored for $2 \mathrm{wk}$.

b $P<0.03$ compared with control group tested by Fisher's exact test. 
A



$\mathrm{HMGBL}++++\quad+\quad+\quad+$

B box - - - - $\quad+\quad+\quad+\quad+$

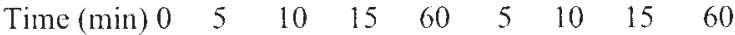

B

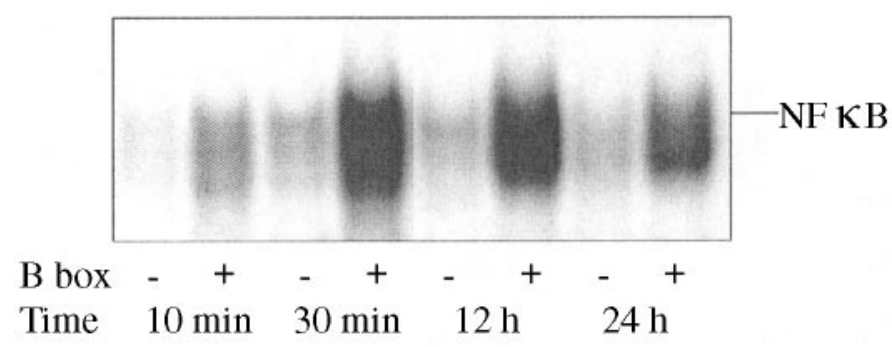

B box

Anti-p65 IgG

Anti-p50 IgG

100x excess unlabeled NF-KB

100x excess unlabeled HIF-1 -

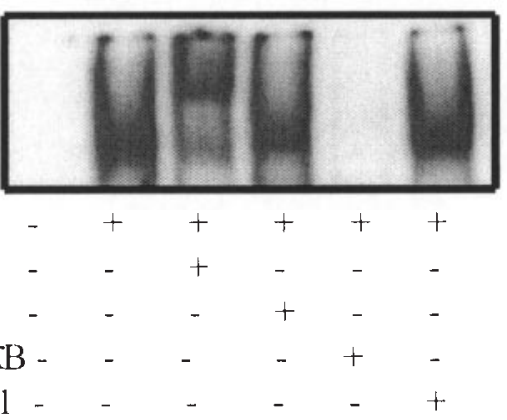

Figure 5. Signal transduction pathways of B box-mediated cytokine release. A: Effects of HMGBI and B box on activation of kinases. Peritoneal macrophages from $\mathrm{C} 3 \mathrm{H} / \mathrm{HeJ}$ mice $\left(2 \times 10^{6} /\right.$ well in $6-\mathrm{cm}$ culture dish) were stimulated with B-box or HMGB1 $(10 \mu \mathrm{g} / \mathrm{mL})$ for the time indicated. Cell lysate was analyzed for kinases (Materials and Methods). Data shown are representative of 3 separate experiments. B: Effect of B box on activation of NF-KB. RAW 264.7 cells in 6-cm culture dishes were incubated for varied time periods with control medium or medium containing $1 \mu \mathrm{g} / \mathrm{mL}$ of $B$ box. After incubation, nuclear proteins were prepared and electrophoretic mobility shift assay performed. Incubation with B box increased NF-kB DNA binding. Results depicted are from a representative experiment, which was repeated 3 times. Nuclear extracts of B box-stimulated RAW 264.7 cells were analyzed by supershift assay using ${ }^{32}$ P-labeled NF-KB. IgG against NF-KB subunits p65 or p50 ( $\left.2 \mu \mathrm{g} / \mathrm{mL}\right)$, $100-$ fold molar excess of unlabeled HIF- 1 (hypoxia-induced factor 1), or NF-kB were added $1 \mathrm{~h}$ before (antibodies) or simultaneously (oligonucleotides) with radiolabelled probe and EMSA was performed. Results are representative of 3 separate experiments.

\section{DISCUSSION}

HMGB1 (or B box) stimulates the release of proinflammatory cytokines such as TNF (13) in cultured macrophages/monocytes and increases the permeability of Caco-2 epithelial cells (24) and inflammatory-promoting activity in cultured endothelial cells (33). HMGB1 also causes acute lung inflammation when administered intratracheally (14) and induces proinflammatory cytokine release in the brain as well as decreases food intake when given into the cerebral ventricles (17). Monocytes/macrophages exposed to endotoxin (LPS), TNF, or IL-1 $\beta$ release HMGB1 with a kinetic response that is significantly delayed as compared with other cytokines (12-15). In vivo, circulating levels of HMGB1 are significantly elevated beginning approximately $8 \mathrm{~h}$ after onset of endotoxemia and reach an elevated, prolonged plateau 10 to $12 \mathrm{~h}$ later $(12,34$, HY and KJT, submitted). Administration of HMGB1 itself is lethal (14) and inhibition of HMGB1 activity rescues animals from lethal systemic inflammation when administered as late as $24 \mathrm{~h}$ after disease onset (HY and KJT, submitted, 34). Together, these studies suggest that HMGB1 may be targeted in a wider therapeutic window for the clinical management of sepsis and other acute systemic inflammatory diseases.

The objective of the studies described here was to explore the relationship between the primary amino acid sequence and cytokine functionality of HMGB1, with the anticipation that the resulting structure and function data will facilitate the development of specific HMGB1 antagonists. We now have demonstrated that B box recapitulates the inflammatory activity of HMGB1, and the principal inflammatory effects mapped to a 20-residue fragment of the full-length protein (HMGB1 residues 89 to 108). These results indicate that a functional proinflammatory cytokine domain resides within the primary amino sequence of the HMGB1 B box and that the B box conveys dual functionality to HMGB1, as both a cytokine and a DNA-binding protein $(8,9)$. Primary amino acid sequences with homology to HMGB1 B box are found in a number of proteins $(3,7,35-38)$; although the function of these proteins is incompletely known, it is interesting to consider that HMGB1 residues 89 to 108 or 
the B box domain may define a previously unrecognized cytokine family.

Administration of B box to D-galactosamine-sensitized mice induced significant lethality independently of endotoxin-induced signaling, suggesting that B box, or sequences or motifs within B box, are sufficient to impart lethal effects during systemic inflammation. The mechanism(s) responsible for lethality induced by $B$ box remain to be elucidated. It is noteworthy, however, that $B$ box induces marked derangements in gastrointestinal mucosal barrier function in mice and increases permeability of cultured human Caco-2 enterocyte-like monolayers (24), suggesting that HMGB1/B box-induced functional alterations in the epithelia of the gut or other organs may contribute to lethal systemic inflammation. The pathological findings in B box-mediated death, including increased hepatocyte apoptosis, are similar to those seen in lethal D-galactosamine/LPS models and differ significantly from the pathology of high dose systemic TNF (39). Interestingly, systemic administration of lethal doses of B box did not induce significant TNF release in the time periods studied, suggesting that B box-mediated lethality may be independent of TNF in D-galactosamine-sensitized mice. The present study suggests an important role of HMGB1 in stimulating macrophages, but does not define the contribution of the pathway to lethality.

The release of large amounts of HMGB1 into the serum compartment can be lethal, but the mechanisms controlling HMGB1 release have been only partially characterized $(21,40)$. HMGB1 lacks a classical signal sequence and may be released through an atypical endolysosomal-like secretory pathway in macrophages and platelets $(12,20,21)$. HMGB1 also can be released from injured or dying somatic and immune cells (22). To date, there is no evidence that the B box itself is produced or released in vivo as an isolated endogenous mediator. However, neutralizing antibodies raised against $B$ box effectively inhibit the cytokine activity of HMGB1 in vitro and attenuate lethality from endotoxemia and sepsis. Therefore, the data presented here identify a potential therapeutic strategy to inhibit the inflammatory activity of HMGB1 by targeting the B box.

Address correspondence and reprint requests to Huan Yang, Laboratory of Biomedical Science, North Shore-Long Island Jewish Research Institute, 350 Community Drive, Manhasset, NY 11030 Phone: 516-562-2314; fax: 516-562-2356; e-mail: hyang@nshs.edu.

Submitted December 19, 2002; accepted for publication January 17, 2003.

\section{REFERENCES}

1. Bustin M. (2001) Revised nomenclature for high mobility group (HMG) chromosomal proteins. Trends Biochem. Sci. 26:152-4.

2. Goodwin GH, Sanders C, Johns EW. (1973) A new group of chromatin-associated proteins with a high content of acidic and basic amino acids. Eur. J. Biochem. 38:14-9.

3. Bianchi ME, Beltrame M, Paonessa G. (1989) Specific recognition of cruciform DNA by nuclear protein HMG1. Science 243:1056-9.

4. Maher JF, Nathans D. (1996) Multivalent DNA-binding properties of the HMG-1 proteins. Proc. Natl. Acad. Sci. U.S.A. 93:6717-20.

5. Hughes EN, Engelsberg BN, Billings PC. (1992) Purification of nuclear proteins that bind to cisplatin-damaged DNA. J. Biol. Chem. 267:13520-7.

6. Melvin VS, Edwards DP. (1999) Coregulatory proteins in steroid hormone receptor action: the role of chromatin high mobility group proteins HMG-1 and -2 .
Steroids 64:576-86.

7. Bustin M, Lehn DA, Landsman D. (1990) Structural features of the HMG chromosomal proteins and their gene. Biochim Biophys Acta. 1049:231-43.

8. Weir HM et al. (1993) Structure of the HMG box motif in the B-domain of HMG1. EMBO J. 12:1311-9.

9. Hardman $\mathrm{CH}$ et al. (1995) Structure of the A-domain of HMGl and its interaction with DNA as studied by heteronuclear 3- and 4-dimensional NMR spectroscopy. Biochemistry 34:16596-607.

10. Baxevanis AD, Landsman D. (1995) The HMG-1 box protein family: classification and functional relationship. Nucleic Acids Res. 23:1604-13.

11. Calogero S et al. (1999) The lack of chromosomal protein Hmgl does not disrupt cell growth but causes lethal hypoglycemia in newborn mice. Nature Genet. 22:276-80.

12. Wang $\mathrm{H}$ et al. (1999) HMG-1 as a late mediator of endotoxin lethality in mice. Science 285:248-51.

13. Andersson U et al. (2000) HMG-1 stimulates proinflammatory cytokine synthesis in human monocytes. J. Exp. Med. 192:565-70.

14. Abraham E, Arcaroli J, Carmody A, Wang H, Tracey KJ. (2000) HMG-1 as a mediator of acute lung injury. J. Immunol. 165:2950-4.

15. Wang $\mathrm{H}$ et al. (1999) Proinflammatory cytokines (tumor necrosis factor and interleukin 1) stimulate release of high mobility group protein-1 by pituicytes. Surgery 126:389-92.

16. Ombrellino $M$ et al. (2000) Increased serum concentrations of high-mobilitygroup protein 1 in hemorrhagic shock. Lancet 354:1446-7.

17. Agnello D, Wang H, Tracey KJ, Ghezzi P. (2002) HMGB1, a DNA-binding protein with cytokine activity, induces brain TNF and IL-6 production, and mediates anorexia and taste aversion. Cytokine 18:231-6.

18. Parkkinen J, Rauvala H. (1991) Interactions of plasminogen and tissue plasminogen activator (t-PA) with amphoterin. Enhancement of t-PA-catalyzed plasminogen activation by amphoterin. J. Biol. Chem. 266:16730-5.

19. Rauvala H, Pihlaakari R. (1987) Isolation and some characteristics of an adhesive factor of brain that enhances neurite outgrowth in central neurons. J. Biol. Chem. 262:16625-5.

20. Degryse B et al. (2001) The high mobility group (HMG) boxes of the nuclear protein HMG 1 induce chemotaxis and cytoskeleton reorganization in rat smooth muscle cells. J. Cell Biol. 152:1192-206.

21. Gardella $S$ et al. (2002) The nuclear protein HMGBI is secreted by monocytes via a non-classical, vesicle-mediated secretory pathway. EMBO Rep. 3:9951001

22. Scaffidi P, Misteli T, Bianchi ME. (2002) Release of chromatin protein HMGB1 by necrotic cells triggers inflammation. Nature 418:191-5.

23. Yang $\mathrm{H}$ et al (2001) The HMG B box confers cytokine activity and signals via RAGE. Shock 15(suppl):27

24. Sappington PL et al. (2002) HMGBI B Box increases the permeability of Caco-2 enterocytic monolayers and impairs intestinal barrier function in mice. Gastroenterology 123:790-802.

25. Wichmann MW, Haisken JM, Ayala A, Chaudry IH. (1996) Melatonin administration following hemorrhagic shock decreases mortality from subsequent septic challenge. J. Surgery Res. 65:109-14.

26. Galanos C, Freudenberg MA, Reutter W. (1979) Galactosamine-induced sensitation of the lethal effects of endotoxin. Proc. Natl. Acad. Sci. U.S.A. 76:5939-43.

27. Lehmann V, Freudenberg MA, Galanos C. (1987) Lethal toxicity of lipopolysaccharide and tumor necrosis factor in normal and D-galactosamine-treated mice. J. Exp. Med. 165:657-63.

28. Bianchi $M$ et al. (1996) Suppression of proinflammatory cytokines in monocytes by a tetravalent guanylhydrazone J. Exp. Med. 183:927-36.

29. Poltorak A et al. (1998) Defective LPS signaling in C3H/HeJ and C57BL/10SCCr mice: mutations in Trr4 gene. Science 282:2085-8

30. Hsu H, Xiong J, Goeddel DV. (1995) The TNF receptor 1-associated protein TRADD signals cell death and NF-KB activation. Cell. 81:495-504.

31. Barnes PJ, Karin M. (1997) Nuclear factor-kB: a pivotal transcription factor in chronic inflammatory diseases. N. Engl. J. Med. 336:1066-71.

32. Hellerbrand C, Jobin C, Licato LL, Sartor RB, Brenner DA. (1998) Cytokines induce NF- $\mathrm{KB}$ in activated but not in quiescent rat hepatic stellate cells. Am. J. Physiol. 275:G269-78.

33. Fiuza $\mathrm{C}$ et al. (2002) Inflammatory promoting activity of HMGBI on human microvascular endothelial cells. Blood. Forthcoming.

34. Ulloa L et al. (2002) Ethyl pyruvate prevents lethality in mice with established lethal sepsis and systemic inflammation. Proc. Natl. Acad. Sci. U.S.A. 99:12351-6.

35. Landsman D, Bustin M. (1993) A signature for the HMG-1 box DNA-binding proteins. Bioessays 15:539-46.

36. Bachvarov D, Moss T. (1991) The RNA polymerase I transcription factor xUBF contains 5 tandemly repeated HMG homology boxes. Nucleic Acids Res. 19:2331-5

37. Van de Wetering $M$, Oosterwegel $M$, Dooijes $D$, Clevers $H$. (1991) Identification and cloning of TCF-1, a T-lymphocyte-specific transcription factor containing a sequence specific HMG box. EMBO J. 10:123-32.

38. Sinclair AH et al. (1990) A gene from the human sex-determining region encodes a protein with homology to a conserved DNA-binding motif. Nature 346:240-4

39. Tracey KJ et al. 1986. Shock and tissue injury induced by recombinant human cachectin. Science 234:470-4.

40. Yang H, Wang H, Tracey KJ. 2001. HMG-1 rediscovered as a cytokine. Shock 15:247-53. 